\title{
Reacting oxide nanoparticles with a substrate
}

\author{
Jonathan P. Winterstein and C. Barry Carter
}

Chemical, Materials and Biomolecular Engineering Dept., University of Connecticut, 191

Auditorium Road Unit 3222, Storrs, CT 06269-3222

Solid-state reactions are frequently encountered in ceramic processing. Titanate electronic ceramics [1] and oxide superconductors [2] are among the many materials synthesized via solidstate reaction. Solid-state reactions may also occur as an unwanted side effect of high-temperature operation of ceramic-containing devices, e.g. pyrochlore-forming reactions in solid oxide fuel cells [3]. The spinel-forming reaction between a periclase-structured oxide and a sesquioxide (sapphire is a favorite) has been studied for many years (see $[4,5]$ ). A variety of reaction geometries have been studied including mixed powders [6], thin films [7] and powders on single crystals [8]. A new geometry using small cubes of magnesium oxide on single-crystal sapphire substrates is investigated here using the TEM. In addition to providing a novel reaction geometry this method permits analysis of particle-substrate interactions that may have broader implications for nanoparticle technology.

Nanocubes of magnesium oxide were produced as smoke particles by burning magnesium metal in air $[9,10]$. Some of the smoke particles were collected on a sapphire substrate pre-thinned to electron transparency. The substrate had a surface orientation of [0001] and the smoke cubes have $\{001\}$ faces so that the initial orientation relationship is limited to $\{001\}_{\mathrm{MgO}} / /(0001)_{\text {sapphire. It is }}$ assumed that the particles are free to rotate in-plane until strong bonds are formed at the interface. The reaction heat treatment is performed ex situ in an air atmosphere. A JEOL 2010 and FEI T12 were used for microscopy.

TEM observations suggest that the particles have some preferred in-plane crystallographic orientations relative to the substrate with low-index planes being nearly aligned. Figure 1 is a BF TEM image of several particles with an in-plane orientation close to $<011>_{\mathrm{MgO}} / /<10 \overline{10}>_{\text {sapphire }}$.

After reaction at $\sim 1100{ }^{\circ} \mathrm{C}$ spinel particles form on the sapphire substrate. The orientation relationship (OR) is predominantly $(111)_{\text {spinel }} / /(0001)_{\text {sapphire }}$ and $[110]_{\text {spinel }} / /[1010]_{\text {sapphire. This OR }}$ requires crystallographic rotation of the spinel relative to the original $\mathrm{MgO}$ during the reaction. This suggests the OR is determined by the sapphire and the starting $\mathrm{MgO}$ cube orientation is irrelevant for these particular reaction conditions. Figure 2 is a diffraction pattern of a specimen after reaction showing the OR. Figure 3 shows the morphology of some particles after the reaction. Many of them form as thin triangular platelets.

[1] S.-S. Ryu and D.-H. Yoon, J Mater Sci 42 (2007) 7093.

[2] X. G. Zheng, Y. Yamashita, H. Matsui, M. Suzuki, M. Taira and C. Xu, J Mater Sci 33 (1998) 1057.

[3] B. C. H. Steele, J Mater Sci 36 (2001) 16.

[4] R. E. Carter, J Am Ceram Soc 44 (1961) 116.

[5] P. G. Kotula and C. B. Carter, J Am Ceram Soc 78 (1995) 248. 
[6] J. Beretka and T. Brown, J Am Ceram Soc 66 (1983) 383.

[7] P. G. Kotula, D. D. Erickson and C. B. Carter, J Am Ceram Soc 77 (1994) 3287.

[8] C. B. Carter and H. Schmalzried, Phil Mag 52 (1985) 207.

[9] R. D. Heidenreich, Phys Rev 62 (1942) 291.

[10] J. D. Nowak, J. P. Winterstein and C. B. Carter, Microsc Microanal 13 (2007) 642 CD.

[11] JPW acknowledges the support of the Air Force through an NDSEG Fellowship.

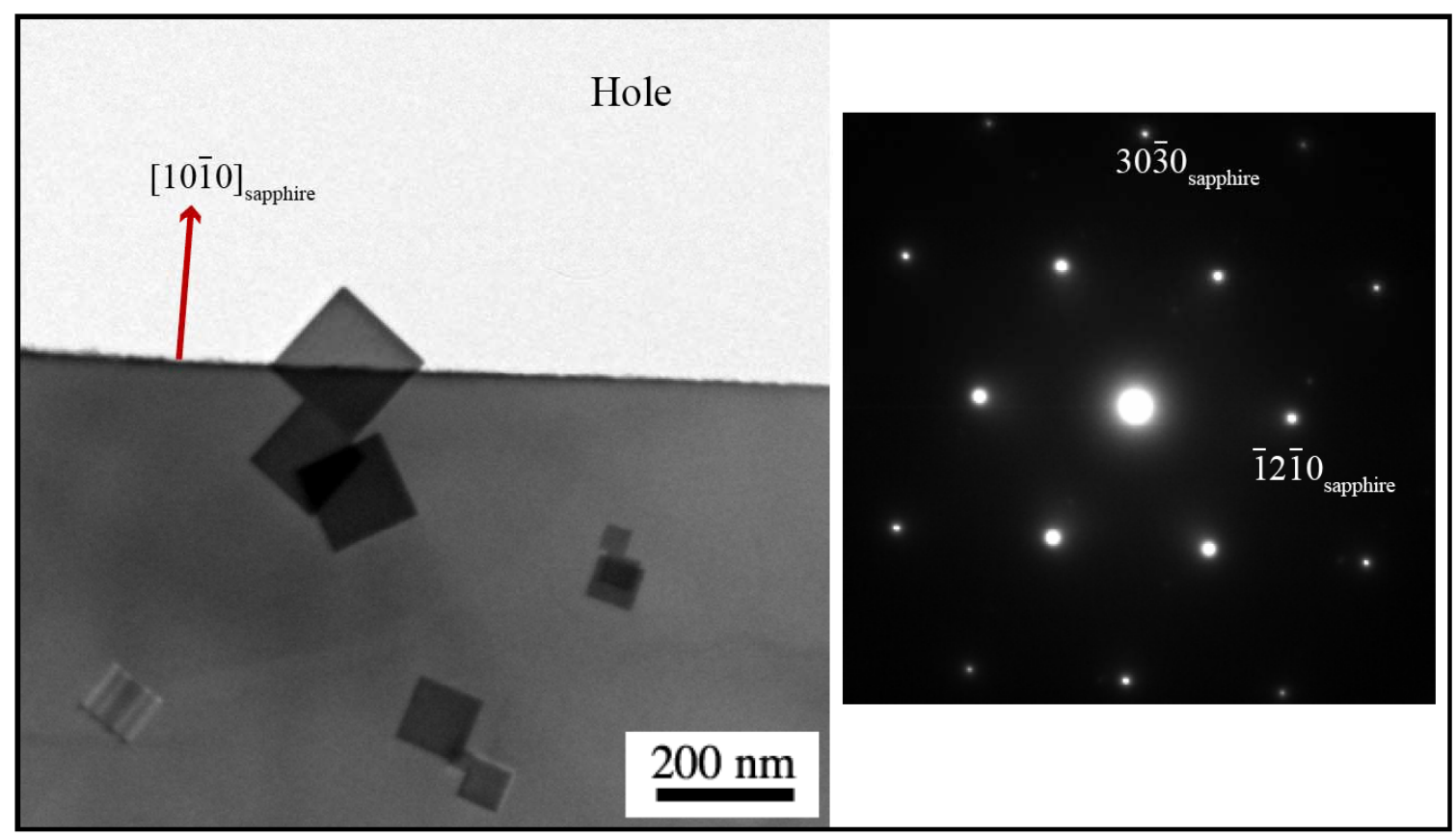

Figure 1: BF TEM image of $\mathrm{MgO}$ nanoparticles on a sapphire substrate with SADP indicating the orientation of the sapphire.

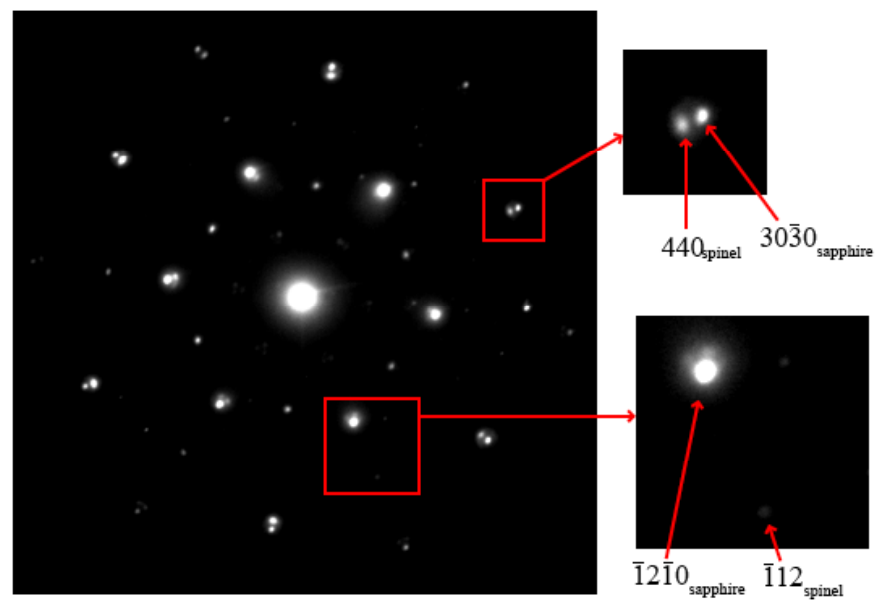

Figure 2: SADP showing the orientation relationship between the spinel phase and the sapphire.

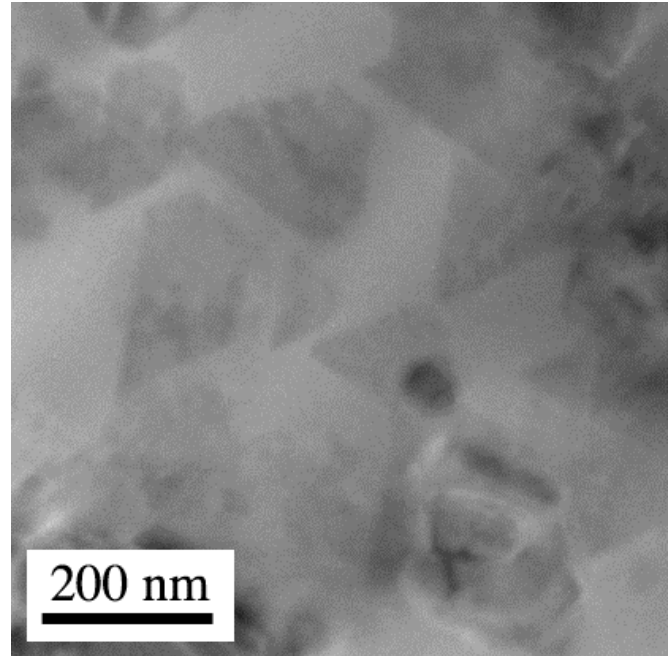

Figure 3: BF TEM image of spinel reaction products as triangular platelets. 